\title{
A peridotite xenolith from garnet- stability field beneath Aitutaki: an implication for small-scale convection
}

\author{
AKIZAWA, N. ${ }^{1}$, OZAWA, K. ${ }^{1}$, WALLIS, S.R. ${ }^{1}$, TAMURA, \\ A. $^{2}$, ISHiKawa, A. ${ }^{3}$, Kogiso, T. ${ }^{4}$ \\ ${ }^{1}$ The Univ. Tokyo, akizawa@aori.u-tokyo.ac.jp (NA), \\ ozawa@eps.s.u-tokyo.ac.jp (KO), swallis@eps.s.u- \\ tokyo.ac.jp (SW) \\ ${ }^{2}$ Kanazawa Univ., aking826@gmail.com \\ ${ }^{3}$ Tokyo Tech., akr@eps.sci.titech.ac.jp \\ ${ }^{4}$ Kyoto Univ., kogiso.tetsu.6s@kyoto-u.ac.jp
}

Garnet peridotite xenoliths have been rarely reported from suboceanic mantle. Because of their rare occurrence, they provide precious petrographic and chemical information of deep suboceanic mantle, and contribute to our understanding of shallow mantle dynamics. We examined a peridotite xenoliths collected at Aitutaki, a member of the Cook-Austral volcanic chain, which are shown to be derived from the garnet-stability field in spite of their absence in garnet. The peridotite xenolith contains reddish fine-grained $(<5 \mu \mathrm{m})$ mineral aggregate (FMA) consisting of olivine, plagioclase, spinel, native iron, and nepheline. The bulk major- and trace-element compositions of FMAs are close to those of pyrope-rich garnet. Chromian spinels enclosed in FMAs forming a cluster of grains apparently isolated in the thin section (2D) have similar crystallographic orientation, indicating that the cluster is a single crystal with extremely irregular 3D morphology. These observations support that the FMA were decomposed garnet and that the aluminous spinel was partially transformed into garnet leaving unreacted $\mathrm{Cr}$ rich component (chromian spinel). Orthopyroxene and clinopyroxene are very homogeneous, but there are slight but discernible chemical zonings in pyroxenes, which are characterized by increase in $\mathrm{Al}, \mathrm{Ca}$, and $\mathrm{Cr}$ from the grain center to the rim for orthopyroxene and increase in $\mathrm{Al}$, decrease in $\mathrm{Ca}$, and $\mathrm{M}$-shaped in $\mathrm{Cr}$ for clinopyroxene. The $\mathrm{Al}$ and $\mathrm{Ca}$ zoning patterns are modeled by diffusional exchange with the other phases induced by pressure and temperature changes. The results show that the peridotite xenolith underwent isothermal decompression on the timescale longer than millions of years. We propose that the peridotite xenolith had been once dragged down and then brought up by small-scale convection (SSC) roll aligning with oceanic plate motion beneath the Cook-Austral volcanic chain. The garnet was decomposed into FMAs triggered by influx of strongly reducing carbonaceous melt/fluid shortly before the xenolith extraction. 